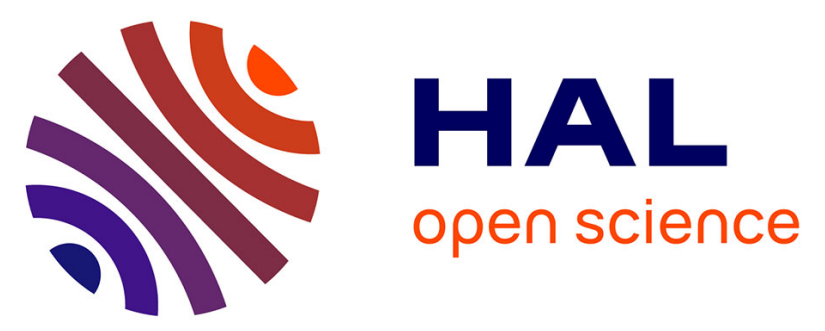

\title{
Influence of a pre-existing glaze layer on the fretting-wear response of HS25 cobalt-based alloy subjected to various temperature conditions
}

Alixe Dreano, Soha Baydoun, Siegfried Fouvry, Sibel Nar, Paco Alvarez

\section{To cite this version:}

Alixe Dreano, Soha Baydoun, Siegfried Fouvry, Sibel Nar, Paco Alvarez. Influence of a pre-existing glaze layer on the fretting-wear response of HS25 cobalt-based alloy subjected to various temperature conditions. Wear, 2022, 488-489, pp.204144. 10.1016/j.wear.2021.204144 . hal-03453446

\author{
HAL Id: hal-03453446 \\ https://hal.science/hal-03453446
}

Submitted on 29 Nov 2021

HAL is a multi-disciplinary open access archive for the deposit and dissemination of scientific research documents, whether they are published or not. The documents may come from teaching and research institutions in France or abroad, or from public or private research centers.
L'archive ouverte pluridisciplinaire HAL, est destinée au dépôt et à la diffusion de documents scientifiques de niveau recherche, publiés ou non, émanant des établissements d'enseignement et de recherche français ou étrangers, des laboratoires publics ou privés. 


\title{
Influence of a pre-existing glaze layer structure on the fretting-wear response of HS25 cobalt-based alloy subjected to various temperature conditions
}

\author{
Alixe Dreano ${ }^{1,2,{ }^{*}}$, Soha Baydoun ${ }^{1}$, Siegfried Fouvry ${ }^{1,{ }^{*}}$, Sibel Nar $^{1}$, Paco Alvarez ${ }^{1}$ \\ ${ }^{1}$ Ecole Centrale de Lyon, Univ Lyon, UMR 5513 LTDS, Ecully, France \\ ${ }^{2}$ Mines Saint-Etienne, Univ Lyon, CNRS, UMR 5307 LGF, Centre SMS, F - 42023 Saint-Etienne France \\ alixe.dreano@emse.fr
}

siegfried.fouvry@ec-lyon.fr

\begin{abstract}
The wear behavior of metallic alloys at variable temperature is a crucial aspect in many industrial components such as the turbine and the compressor components in aircraft engines. The blade/disk contact is subjected to a cyclic thermal loading combined with a cyclic sliding (fretting) which can significantly damage the interface. The studied contact is a Haynes 25 (cobalt-based alloy) sample fretted against alumina in a cross-cylinder configuration. At a temperature lower than $T_{G L}=300^{\circ} \mathrm{C}$, high abrasive wear rate is detected. Above this threshold temperature $\left(T_{G L}\right)$, a protective third body referred to as "glaze layer" is spontaneously created at the interface. This layer exhibits excellent tribological properties which lead to a nearly unworn regime.

The objective of this work is to establish how a pre-glaze layer formed during an initial high temperature sequence $\left(T=575^{\circ} \mathrm{C}\right)$ behaves when it is submitted to a lower temperature fretting sliding sequence. Results show that even if the glaze layer is destroyed at low temperature, there is a "memory" effect which reduces the wear volume compared to a standard fretting test performed at a fixed temperature condition (without pre-glaze layer formation). It is also demonstrated that the glaze layer is destroyed within a latency time at low temperature. Moreover, when the glaze layer is turned into debris, it enriches the debris bed with a high proportion of cobalt element. This high concentration of cobalt element in the third body layer can clarify the lower steady state wear regime compared to an equivalent fixed temperature test condition.
\end{abstract}

\section{Keywords}

Fretting; High Temperature; Glaze layer; Adhesive Wear; Third Body. 


\section{Introduction}

There are a lot of studies in the literature dealing with the influence of temperature on the wear mechanisms of various alloys. A decrease of the wear volume for high temperatures is observed for steels [1,2], Ni-based alloys [3,4] or Co-based alloys [5-7]. This wear reduction is attributed to the formation of a protective and compact layer at the interface, made of oxidized debris generated at the beginning of the wear process. The so-called "glaze layer " is made of nanocrystalline oxides which are sintered together $[5,8,9]$. The sintering process was highlighted by Kato et al. $[8,10]$ with the introduction of different oxides in the interface during sliding. The authors demonstrated that oxides with good diffusion properties are able to create a glaze layer even at low temperature. Then, the tribo-sintering process is promoted by the diffusion properties of the species involved in the interface as well as the temperature and the debris size [11]. For cobalt-based alloy interfaces, it was showed that the diffusion properties of the cobalt oxide are greater than those of chromium oxides (considering $20 \mathrm{w} . \%$ of $\mathrm{Cr}$ in the based material) leading to a faster sintering process of cobalt oxide particles $[5,9]$. Hence, the glaze layer is mainly formed of $\mathrm{Co}_{3} \mathrm{O}_{4}$ nanocrystalline particles.

When the glaze layer is effective at the interface, the friction coefficient decreases and the wear process stops in a macroscopic point of view [9]. The exceptional tribological properties of the glaze layer are not completely understood. Two hypotheses are proposed in the literature:

- Stott [12] and Viat [13] explained the tribological properties of the glaze layer by the plastic flow/ductility of the latter. The absence of fragility of the glaze layer induces a remarkable wear reduction.

- Dreano et al proposed [9], as also briefly mentioned in [12,14], that the absence of wear of the glaze layer may be explained by a continuous sintering process during sliding. Hence, the glaze layer wear debris is continuously reincorporated in the third body layer. By excluding the debris ejection process from the interface, this exclusive recirculation process of the glaze layer material under high temperature conditions leads to a zero wear volume condition.

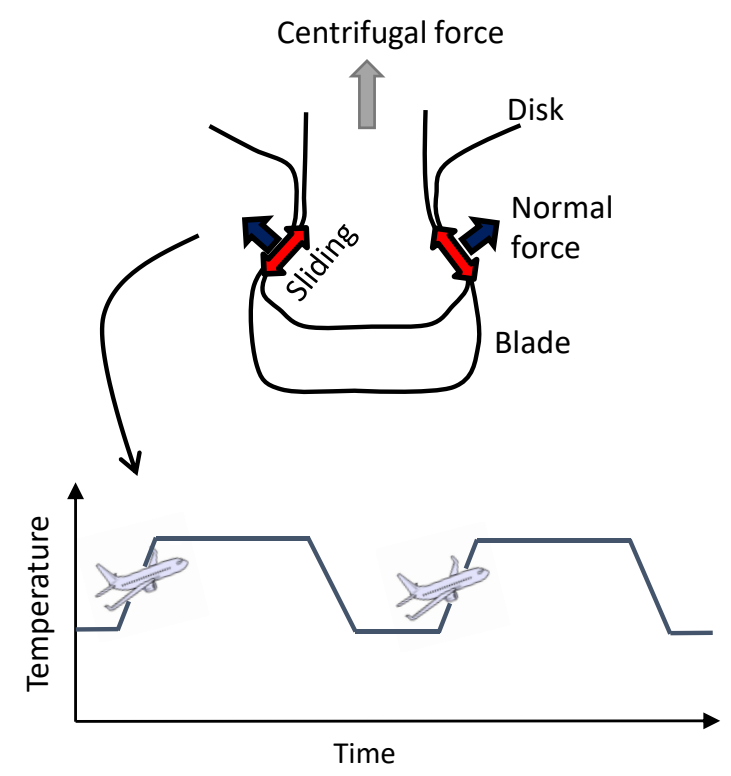

Figure 1: Illustration of the blade/disk contact in an aircraft engine and the evolution of the temperature at the interface. 
Understanding the wear behavior of metallic alloys operating at variable temperatures has been a constant target for many industrial applications such as the turbine and the compressor assemblies in aircraft engines $[7,15,16]$. The blade/disk contact is submitted to a cyclic thermal loading combined with a cyclic sliding (fretting) which can considerably damage the interface (Figure 1). The operating temperature for the blade/disk contact is between $200^{\circ} \mathrm{C}$ and $450^{\circ} \mathrm{C}$ for the high pressure compressor [17] and up to $700^{\circ} \mathrm{C}$ for the low pressure turbine [15]. However, the influence of variable temperature conditions on the interface was barely studied in the literature even if it has an vital interest from an industrial point of view.

Glascott [18] studied the thermal cycling effect on the glaze layer stability and demonstrated that heating or cooling period has no influence on the tribological behavior of the glaze layer if the system is not running during this period. Hence, he suggested that the thermal stress induced by such temperature variation has no effect on the glaze layer which remains compact and adherent to the substrate. However, if the glaze layer is examined at ambient temperature, Glascott showed that the friction coefficient increases abruptly. The glaze layer is fractured and ejected out of the interface. He concluded that the instability of the glaze layer is due to a mechanical effect. Rybiak et al. [2] also studied the effect of the thermal cycling on a glaze layer subjected to fretting. They also noticed that the glaze layer is stabilized at high temperature and becomes unstable if the temperature is reduced above a critical temperature $T_{G L}$. If the temperature increases again up to $T_{G L}$, the glaze layer is once again effective. Rybiak and co-authors concluded that the transition stability/instability is very fast compared to the latency time required to form the glaze layer. They suggested that the tribological behavior change is not related to a destruction/re-building of the glaze layer but rather due to a reversal response of the third body mechanical and rheological properties.

From the work of Glascott and Rybiak, it is possible to conclude that the tribological behavior of the glaze layer is mainly driven by the temperature. If the temperature is lower than $\mathrm{T}_{\mathrm{GL}}$, the glaze layer is brittle and does not withstand the sliding process whereas if the temperature is higher than $\mathrm{T}_{\mathrm{GL}}$, the glaze layer is more ductile and does not undergo wear. However, it is still unclear how the glaze layer behaves since the previous aforementioned studies had contradictory conclusions. Thus, it is proposed here to perform variable temperature fretting wear experiments to observe the wear behavior of the glaze layer. The background of the studied interface (HS25/alumina in cross-cylinder configuration) is very rich $[5,9,19-21]$ in term of glaze layer formation so that the present study focuses on this particular interface.

\section{Materials and experimental set-up}

\subsection{Materials}

A cobalt-based alloy (HS25) is used in this work and is fretted against alumina. The chemical composition of HS25 is presented in Table 1. Alumina sample was chosen as a counter body for its high mechanical resistance and for its chemical inertness.

Table 1: Nominal composition of the Haynes 25 alloy (at. \%) extracted from supplier documentation.

\begin{tabular}{|l|l|l|l|l|l|l|l|}
\hline Co & $\mathrm{Cr}$ & $\mathrm{Ni}$ & $\mathrm{W}$ & $\mathrm{Fe}$ & $\mathrm{Mn}$ & $\mathrm{Si}$ & $\mathrm{C}$ \\
\hline 54 & 24 & 11 & 5 & 3.3 & 1.6 & 0.7 & 0.4 \\
\hline
\end{tabular}




\subsection{Experimental set-up}

The tribosystem consists of a crossed-cylinder contact configuration as presented in Figure 2a. The rods have a diameter of $8 \mathrm{~mm}$ leading to an equivalent sphere-on-flat contact.

a)

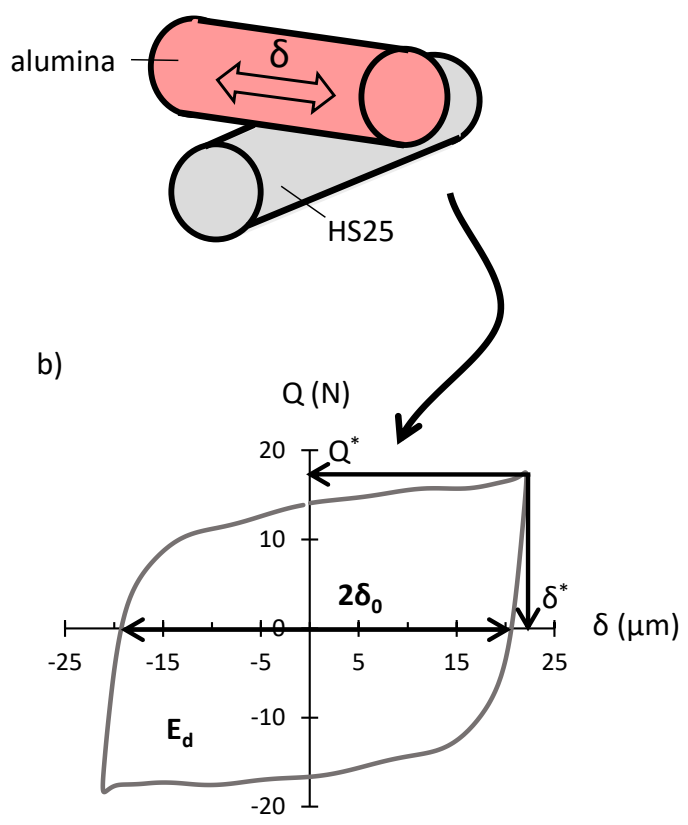

Figure 2: a) Alumina/HS25 cross-cylinder configuration; b) Fretting loop (reprinted from [9] with permission

from Elsevier).

The high temperature fretting bench used in the present study was previously presented in [21]. It is composed of a fixed part rubbed against a moving part which is set in motion by an electromagnetic shaker. The specimens are fixed to the sample holders and pressed with a normal force $P$. The normal force $P$ is recorded along the test as well as the relative displacement $\delta$ and the tangential force $Q$. Fretting loops, showing the evolution of $Q$ versus $\delta$, are plotted for each cycle as presented in Figure $2 \mathrm{~b}$. The sliding amplitude $\delta_{0}$ is then defined as the real displacement at the interface and measured when the tangential force $Q$ is equal to 0 (Figure $2 \mathrm{~b}$ ). All the tests were conducted by monitoring the sliding amplitude $\delta_{0}$ which is fixed for the whole study at $\pm 20 \mu \mathrm{m}$.

During the test, the friction coefficient was computed using Eq. (1)

$$
\mu=\frac{Q^{*}}{P}
$$

Where $Q^{*}$ is the amplitude of the tangential force recorded during one cycle.

\subsection{Wear volume measurements and morphological analysis of the wear tracks}

After the tribological tests, the samples were cleaned in an ultrasonic bath with ethanol in order to remove the loose debris particles. Fretting scars were optically observed and topography scans were performed and analyzed using an interferometric BRUKER system (Figure 3). No wear volume is observed on the alumina counterparts; therefore, the wear volume of the tribosystem is equal to the missing volume on the HS25 sample. 


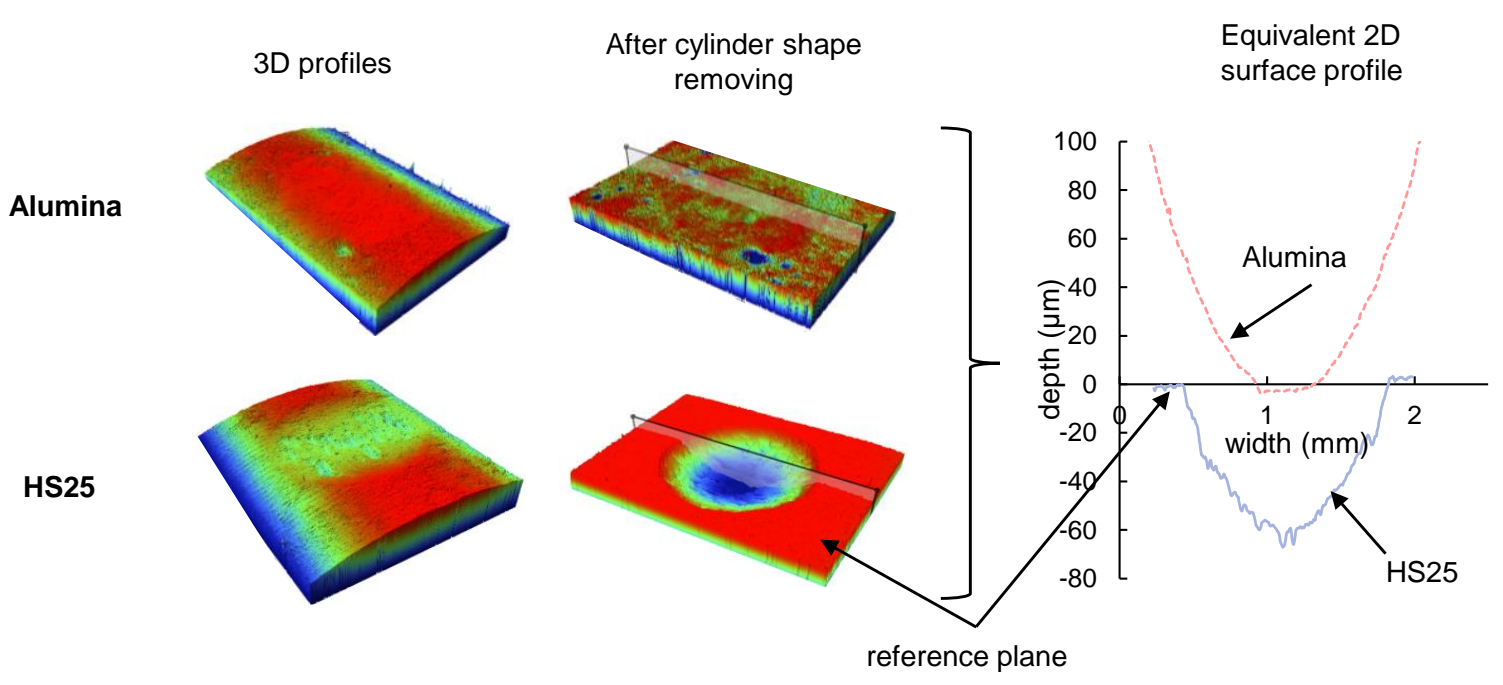

Figure 3: Illustration of the wear volume analysis (reprinted from [21] with permission from Elsevier).

The wear tracks were observed with an optical microscope and an SEM (FEG Mira 3 TESCAN) using an accelerating voltage of $5 \mathrm{kV}$. The EDX quantifications were performed with an Oxford Instruments system at $20 \mathrm{kV}$ (the interaction volume is then around $1 \mu \mathrm{m}^{3}$ ).

\section{Formation and stability of the glaze layer}

\subsection{Fretting experiments}

As the stability of the glaze layer is an important issue for industrial systems, it is first proposed to investigate the friction and wear behaviour of the glaze layer when applying various temperature sequences. Two kinds of temperature sequences experiments were compared to establish the effect of the initial glaze layer formation on the studied tribo-system wear response (Figure 4).

a) «Fixed Temperature» experiment (FT experiment)

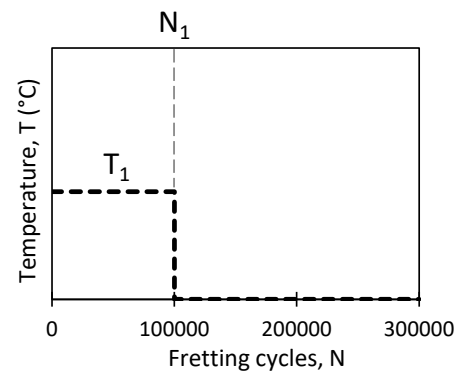

b)

«Variable Temperature» experiment (VT experiment)

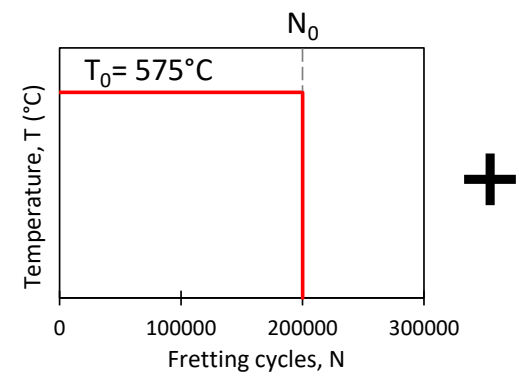

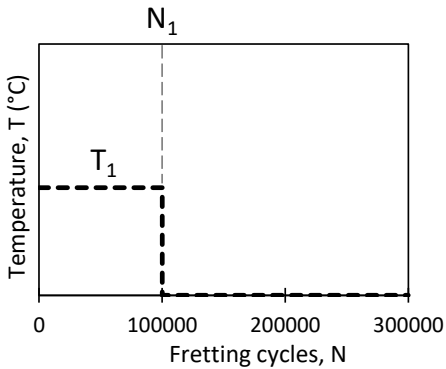

Figure 4: Design of the fretting wear experiments: (a) Fixed Temperature experiment (FT experiment) and (b) Variable Temperature experiment (VT experiment).

First, fixed temperature experiments ("FT experiments" in Figure 4a) were done in a classical way, where a constant temperature $T_{1}$ is imposed on the sample during $N_{1}$ cycles. Secondly, to examine the behaviour of the glaze layer at lower temperature, some variable temperature experiments ("VT experiments" in Figure 4b) were also performed. An initial glaze layer is created at a temperature $T_{0}=$ $575^{\circ} \mathrm{C}$. In order to be consistent with the previous studies on such contact $[5,9,19-21]$, the number of 
fretting cycles is fixed at $\mathrm{N}_{0}=200000$. Then, the interface is tested at a temperature $T_{1}$ during $\mathrm{N}_{1}$ cycles as those applied for the previous plain fixed temperature (FT) sequence. The values of the tribological parameters are displayed in Table 2.

Table 2: Tribological parameters for the FT and VT experiments.

\begin{tabular}{|c|c|c|c|c|c|c|}
\hline & & $\begin{array}{c}\text { Temperature, } \\
\mathrm{T}\end{array}$ & $\begin{array}{c}\text { Normal Force, } \\
\mathrm{P}\end{array}$ & $\begin{array}{c}\text { Sliding } \\
\text { amplitude, } \\
\delta_{0}\end{array}$ & $\begin{array}{c}\text { Frequency, } \\
\mathrm{f}\end{array}$ & $\begin{array}{c}\text { Number of } \\
\text { fretting } \\
\text { Cycles, } \mathrm{N}\end{array}$ \\
\hline \multirow{2}{*}{$\begin{array}{c}\text { VT } \\
\text { experiments }\end{array}$} & Bloc 0 & $\mathrm{T}_{0}=575^{\circ} \mathrm{C}$ & $50 \mathrm{~N}$ & $\pm 20 \mu \mathrm{m}$ & $50 \mathrm{~Hz}$ & $\mathrm{~N}_{0}=200000$ \\
\cline { 2 - 7 } & Bloc 1 & $\mathrm{~T}_{1}$ & $50 \mathrm{~N}$ & $\pm 20 \mu \mathrm{m}$ & $50 \mathrm{~Hz}$ & $\mathrm{~N}_{1}=100000$ \\
\hline \multicolumn{2}{|c|}{ FT experiments } & $\mathrm{T}_{1}$ & $50 \mathrm{~N}$ & $\pm 20 \mu \mathrm{m}$ & $50 \mathrm{~Hz}$ & $\mathrm{~N}_{1}=100000$ \\
\hline
\end{tabular}

\subsection{Friction and wear behaviour}

Figure $5 \mathrm{a}$ and Figure $5 \mathrm{~b}$ display the results of the "Variable Temperature" retting tests performed between $25^{\circ} \mathrm{C}$ and $600^{\circ} \mathrm{C}$, in tem of the wear volume and the friction coefficient as a function of the temperature $\mathrm{T}_{1}$. These results are compared to the "Fixed Temperature" tests obtained when the contact is tested simply at a fixed temperature $T_{1}$ fretting wear sequence.
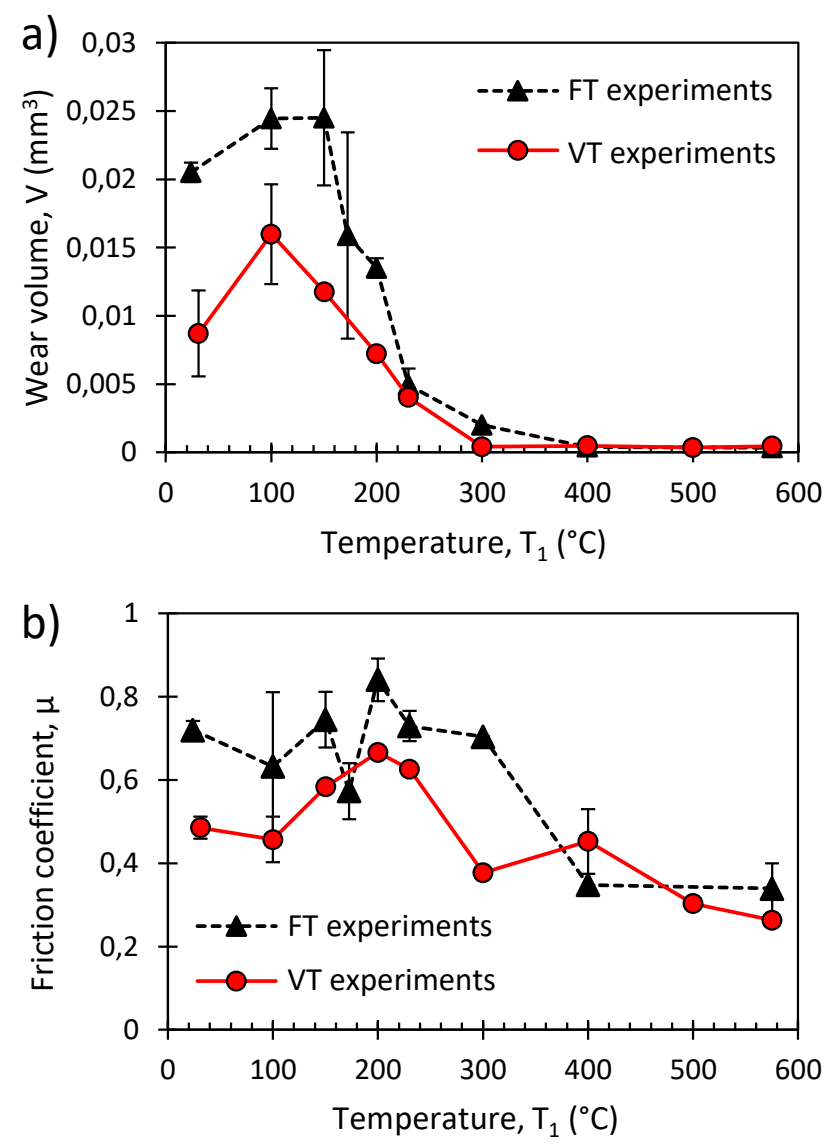

Figure 5 : Evolution of the wear volume (a) and the friction coefficient (b) as a function of the temperature $T_{1}$ for Fixed Temperature and Variable Temperature experiments ( $f=50 \mathrm{~Hz}, \mathrm{P}=50 \mathrm{~N}, \delta_{0}= \pm 20 \mu \mathrm{m}, \mathrm{N}_{1}=100000$ cycles). 


\subsubsection{The effect of the temperature on the glaze layer formation: analysis of the FT experiments}

As shown in $[9,20,21]$ and in Figure 5 (FT experiments), three domains can be observed depending on the temperature. The low temperature domain $\left(T \leq 150^{\circ} \mathrm{C}\right)$ presents an increase of the wear volume up to a maximum value achieved for $\mathrm{T}=150^{\circ} \mathrm{C}$. The friction coefficient is quite high and unstable (between 0.57 and 0.74). According to [9], where the same kind of curve was plotted (for a higher number of cycles), the associated wear kinetics is linear over the fretting cycles. The typical wear scars of this domain exhibits some abrasive grooves and a powdered debris bed layer with the absence of a tribolayer (Figure 7 at $100^{\circ} \mathrm{C}$ ). The medium temperature domain $\left(150^{\circ} \mathrm{C}<\mathrm{T}<300^{\circ} \mathrm{C}\right.$ ) displays a sharp decrease in the wear volume until a very low value at $300^{\circ} \mathrm{C}$. The friction coefficient also presents a decreasing trend from 0.84 to 0.34 . The wear tracks presented in Figure 7 at $200^{\circ} \mathrm{C}$, shows the presence of a bright layer at the interface protecting it from severe wear. The high temperature domain $\left(T \geq 300^{\circ} \mathrm{C}\right)$ is characterized by a very low wear volume. The wear kinetics at $575^{\circ} \mathrm{C}$ presented in [9] shows the same, but a more pronounced, bi-linear evolution compared to medium temperatures.

\subsubsection{The effect of the temperature on the glaze layer stability: analysis of the VT experiments}

According to Figure $5 \mathrm{a}$, it is observed that the glaze layer created at a temperature of $575^{\circ} \mathrm{C}$ is able to resist fretting loadings for lower temperatures, until $300^{\circ} \mathrm{C}$. Indeed, the wear volume is very low for the range $\left[300^{\circ} \mathrm{C}-575^{\circ} \mathrm{C}\right]$ and equals to the wear volume obtained for a fixed temperature test at $575^{\circ} \mathrm{C}$. For temperatures lower than $300^{\circ} \mathrm{C}$, the wear volume of the VT tests increases which implies the destruction of the glaze layer. This trend is confirmed by optical observations in Figure 7. However, Figure 5 already confirms that the glaze layer is unable to withstand low temperatures and is wearing during the experiments. Hence, the temperature of the glaze layer formation is equivalent to the temperature of the glaze layer destruction. In term of friction coefficient, as observed in Figure $5 \mathrm{~b}$, the friction coefficient also increases for temperature lower than $300^{\circ} \mathrm{C}$, marking also the destruction of the glaze layer.

In addition, for $\mathrm{T} \leq 200^{\circ} \mathrm{C}$, the wear volumes for VT experiments are surprisingly lower than those obtained for the FT tests. The same trend is observed for the friction coefficient analysis. Hence, this suggests that the introduction of a pre-glaze layer structure, generated during an initial high temperature sequence, reduces the friction coefficient as well as the wear volume created during the successive low temperature sequence. On the other hand, despite its instability under low temperature $\left(\mathrm{T}<300^{\circ} \mathrm{C}\right)$, the introduction of a pre-glaze layer structure generated during an initial high temperature sequence tends to decrease the fretting wear kinetics when the temperature is lowered below a threshold glaze layer stability temperature $\mathrm{T}_{\mathrm{GL}}=300^{\circ} \mathrm{C}$.

\subsection{Analysis of the wear coefficients}

In order to better understand the memory effect of the protective glaze layer, Figure 6 shows the evolution of the apparent Archard's wear coefficients $k_{\text {app }}\left(\mathrm{mm}^{3} / \mathrm{J}\right)$ as a function of the temperature $\mathrm{T}_{1} . k_{a p p}$ is calculated according to Eq.2:

$$
k_{a p p}=\frac{V_{1}}{\sum W_{1}}
$$

Where $V_{1}$ and $\sum W_{1}$ are related to the fretting bloc referred to as " 1 " in Figure 4 . Figure $6 \mathrm{~b}$ shows the evolution of $\Delta k_{a p p}$, defined in Eq. 3 , as a function of the temperature $\mathrm{T}_{1}$.

$$
\Delta k_{a p p}=k_{a p p}(F T)-k_{a p p}(V T)
$$


a)
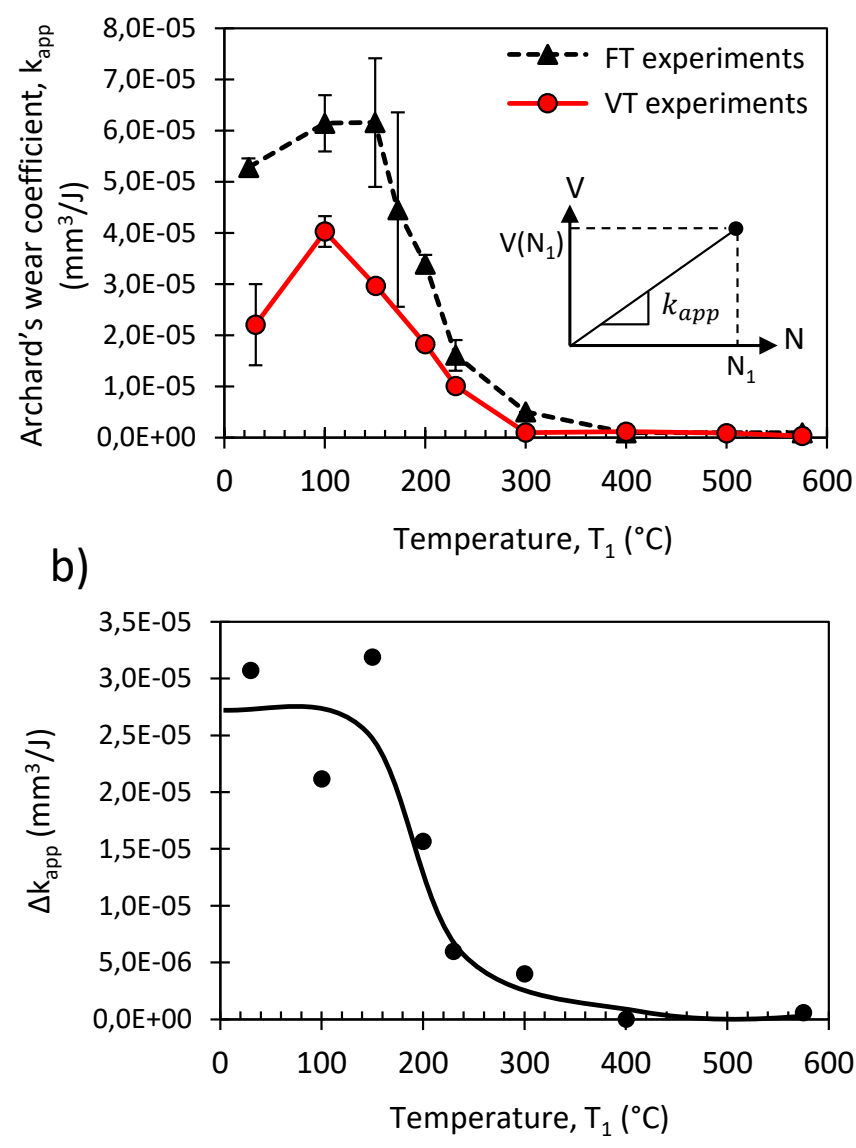

Figure 6: a) Evolution of the apparent Archard's wear coefficient for the FT and VT experiments with the temperature; b) evolution of $\Delta k_{a p p}=k_{a p p}(F T)-k_{a p p}(V T)$ as a function of the temperature $(\mathrm{f}=50 \mathrm{~Hz}, \mathrm{P}=50$ $\mathrm{N}, \delta_{0}= \pm 20 \mu \mathrm{m}, \mathrm{N}_{1}=100000$ cycles).

It can be concluded that the introduction of an initial high temperature fretting bloc (formation of a pre-glaze layer) reduces the Archard's wear coefficient, especially at low temperature. Once again, a beneficial effect of the glaze layer pre-formation is observed regarding the global wear rate. To interpret this apparent wear rate evolution over the temperature, it is also interesting to investigate the fretting scar morphology and the corresponding wear process.

\subsection{Optical and EDX analysis}

To deepen the current investigation, morphological analysis of the wear tracks is observed. First, optical images of the wear scars at $100^{\circ} \mathrm{C}, 200^{\circ} \mathrm{C}, 300^{\circ} \mathrm{C}, 400^{\circ} \mathrm{C}$ and $500^{\circ} \mathrm{C}$ are presented in Figure 7 . At a first sight, it seems that there is no significant difference between wear scars when tested at variable or fixed temperature conditions. It can be presumed that the wear mechanisms of the VT experiments involved for each temperature do not differ too much from the ones observed for FT experiments. Hence, at $100^{\circ} \mathrm{C}$, an abrasive wear mechanism takes place with or without the preexistence of a glaze layer. At $200^{\circ} \mathrm{C}$, for both VT and FT experiments, the wear mechanism changes from a severe abrasive wear to a mild wear with the formation of a compact layer at the interface. 
For higher temperatures, a glaze layer is formed at the interface protecting it from further wear for both FT and VT experiments. Then, the formation of a glaze layer before being fretted at lower temperature does not change the wear mechanisms involved for each temperature.

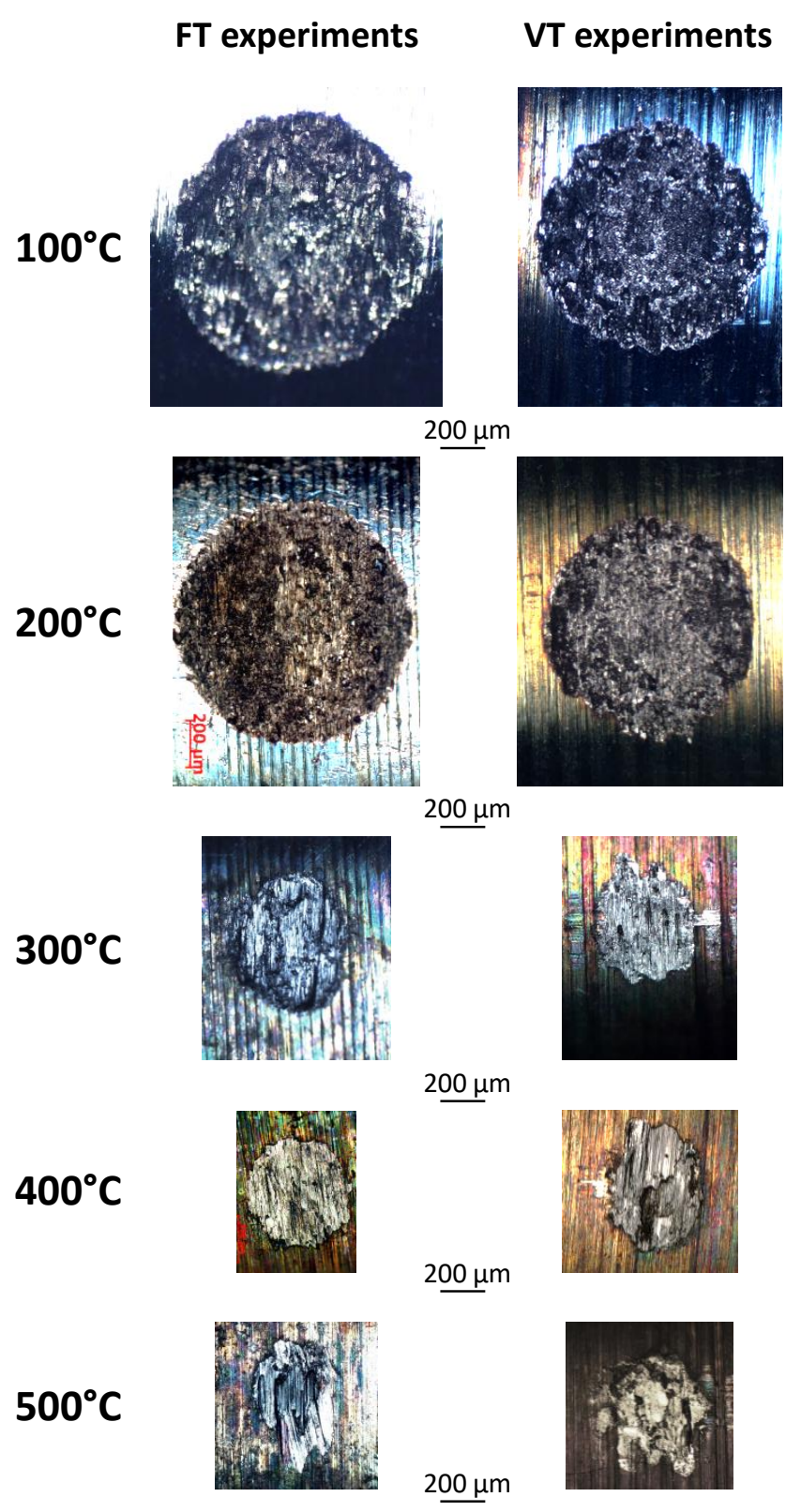

Figure 7: optical images of the wear tracks after being fretted at different temperatures ( $f=50 \mathrm{~Hz}, \mathrm{P}=50 \mathrm{~N}, \delta_{0}$

$$
= \pm 20 \mu \mathrm{m}, \mathrm{N}_{1}=100000 \text { cycles). }
$$

Additional investigations were performed using EDX analysis (Figure 8) showing the evolution of the atomic ratio $\mathrm{Co} / \mathrm{Cr}$ of the wear tracks as a function of the temperature. Previous research $[9,19]$ demonstrated that the glaze layer is enriched in Co elements, promoting a fast tribo-sintering process due to its good auto-diffusion properties. In contrary, Cr elements, which represent 24 at. \% of the based material, seem to have a bad effect on the glaze layer formation [5,9]. The observation of the variation of the $\mathrm{Co} / \mathrm{Cr}$ ratio is then relevant considering that $\mathrm{HS} 25$ is mainly composed of Co (54 at. \%) and $\mathrm{Cr}$ (24 at.\%). Then, some global EDX maps were performed on the wear tracks (see Figure 8a) and the atomic percentages of $\mathrm{Co}$ and $\mathrm{Cr}$ were averaged over the surface. Even if the EDX 
quantification has a pretty much high resolution (around $1 \mu \mathrm{m}$ at $20 \mathrm{keV}$ ), some information can be extracted from Figure 8b. First, EDX analysis on HS25 shows that the initial atomic ratio $\mathrm{Co} / \mathrm{Cr}$ is equal to 2, which is in agreement with Table 1. For the Fixed Temperature experiments, it is observed that the $\mathrm{Co} / \mathrm{Cr}$ ratio is quite constant for $\mathrm{T}<400{ }^{\circ} \mathrm{C}$, around $2.3 / 2.4$. It means that there is slightly more cobalt than chromium elements, compared to the initial composition. At high temperature $(T=$ $575^{\circ} \mathrm{C}$ ), there is a huge increase of the $\mathrm{Co} / \mathrm{Cr}$ ratio towards 4 . This result confirms a previous work on this topic [19]. However, at $400^{\circ} \mathrm{C}$, it is quite surprising to achieve such a low $\mathrm{Co} / \mathrm{Cr}$ ratio since the glaze layer is already effective at the interface. This can be explained by the fact that at this temperature, the oxidation process is less pronounced than at $575^{\circ} \mathrm{C}$, resulting in a thinner oxidized layer and then a lower $\mathrm{Co} / \mathrm{Cr}$ ratio than expected.

a)

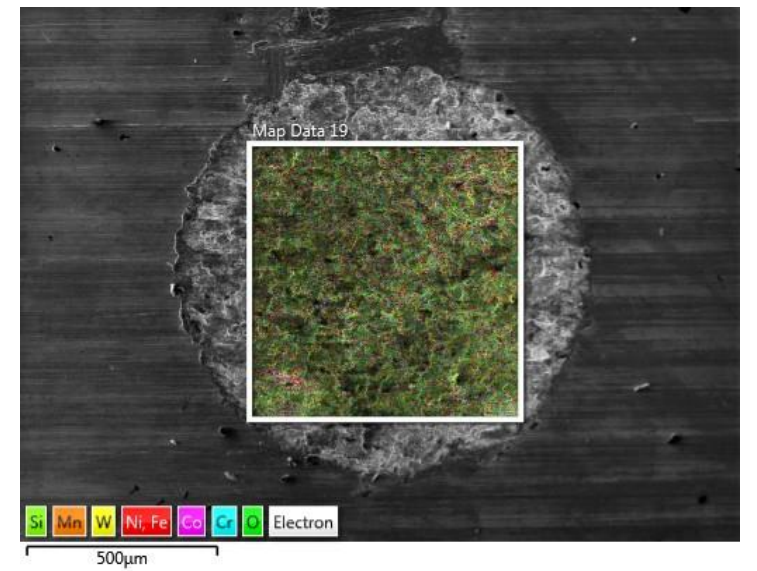

b)

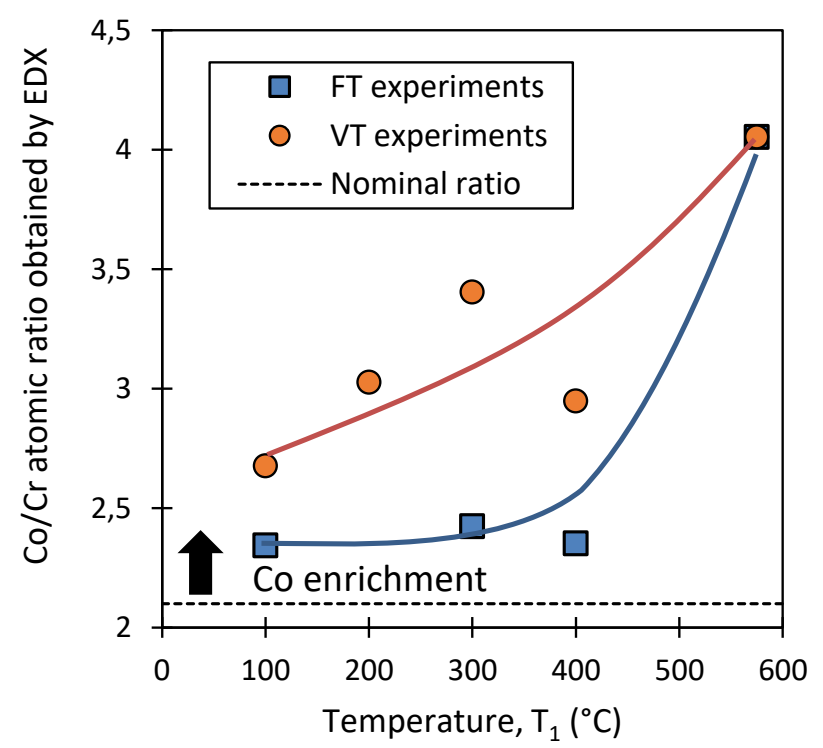

Figure 8: a) Illustration of the EDX map performed for each scar from which the mean atomic percent of $\mathrm{Co}$ and $\mathrm{Cr}$ has been extracted; (b) Evolution of the $\mathrm{Co} / \mathrm{Cr}$ atomic ratio in the wear tracks as a function of the temperature.

A more interesting aspect concerns the comparison of the $\mathrm{Co} / \mathrm{Cr}$ ratio evolution between $\mathrm{FT}$ and VT experiments. VT tests confirm an increase of the $\mathrm{Co} / \mathrm{Cr}$ ratio with the temperature. However, the $\mathrm{Co} / \mathrm{Cr}$ ratio in the latter is systematically higher than that observed for FT conditions. Hence, it can be concluded that the high Co concentration generated during the pre-glaze layer formation phase is still effective even in the successive low temperature fretting wear sequences. 


\subsection{Discussion}

This first experimental campaign reveals the effect of the formation of an initial glaze layer on the wear and friction behavior of the interface fretted at various temperatures. It is shown that the domain of the creation of the glaze layer $\left(\mathrm{T}>300^{\circ} \mathrm{C}\right)$ is also similar to the domain of the stability of the glaze layer. However, the introduction of a glaze layer structure is unable to prevent the fretting wear damage when the temperature is lowered below the threshold stability temperature $T_{G L}=300{ }^{\circ} \mathrm{C}$ confirming the previous work of Glascott [18] and Rybiak [2]. Additionally, a small "memory effect" is discerned as the wear volume, the friction coefficient and the Archard's wear coefficients are lower when the glaze layer structure is previously formed at the interface (Figure 5 and Figure 6). According to the morphological observation of the wear tracks (Figure 7), there is no change in the wear mechanism involved for each temperature whether the glaze layer was created or not. In other words, for low temperatures, even if a glaze layer was previously formed at the interface, the activated wear mechanism remains oxidative-abrasive [21]. However, the presence of an initial glaze layer has an influence on the chemical composition of the wear tracks for all the tested temperature, as presented in Figure 8. There is more cobalt in the wear tracks when a glaze layer has been firstly formed at the interface than when no glaze layer is present at the beginning of the test. Hence, this sort of "memory" effect observed for low temperatures can be attributed to the chemical nature of the wear tracks and the debris embedded in the interface. To go further in the analysis, it is now proposed to focus the investigation for one particular VT experiments $\left(575^{\circ} \mathrm{C}-100^{\circ} \mathrm{C}\right)$ and to probe profoundly the dynamical destruction of the glaze layer when low temperature fretting cycles are applied successively.

\section{Dynamical wear analysis at $100^{\circ} \mathrm{C}$}

\subsection{Fretting experiments}

The experimental results detailed in this section are schematized in Figure 9. First, a glaze layer is created at $575^{\circ} \mathrm{C}$ during $\mathrm{N}_{1}$ cycles $(=200000)$. Then, the temperature is set to $100^{\circ} \mathrm{C}$. The number of fretting cycles of the bloc 2 is varied in the range from 0 to 100000 fretting cycles in order to capture the destruction of the previous glaze layer structure as well as the wear process activated under low temperature condition. 


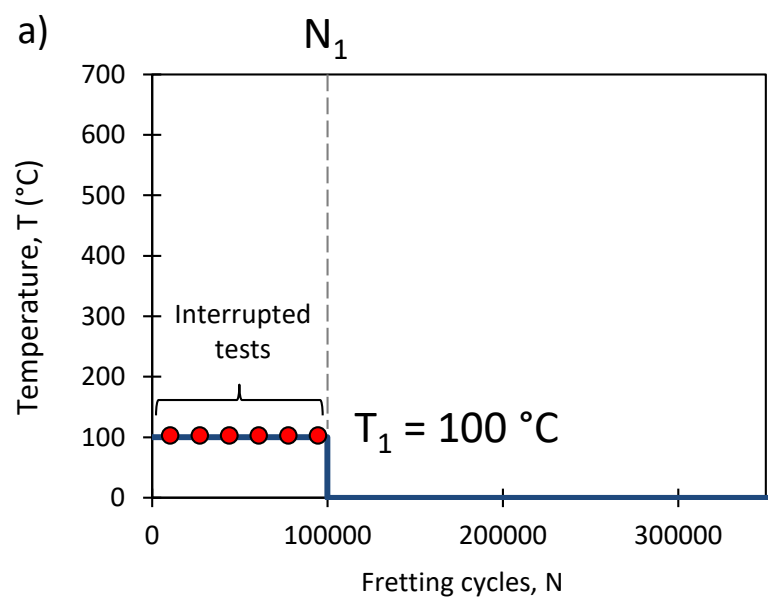

FT experiments

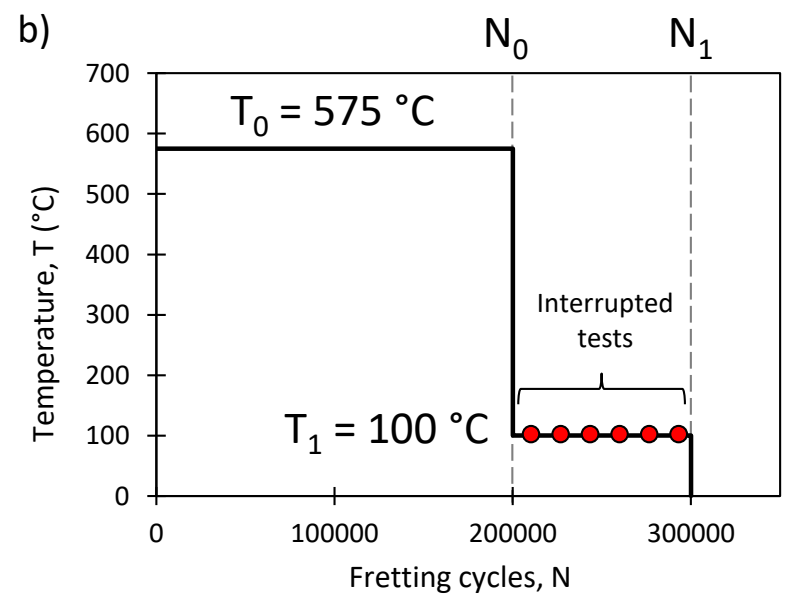

VT experiments

Figure 9: Design of the fretting wear experiments for the dynamical wear analysis at $100^{\circ} \mathrm{C}$ : (a) Fixed

Temperature experiment (FT experiment) and (b) Variable Temperature experiment (VT experiment).

\subsection{Wear kinetics}

Figure 10a displays the evolution of the wear volume extension over the entire temperature sequence $\left(575^{\circ} \mathrm{C}-100^{\circ} \mathrm{C}\right.$ ) and Figure $10 \mathrm{~b}$ presents the corresponding glaze layer coverage (in \%) as introduced in Eq. 4:

$$
\text { Percentage of glaze layer }=\frac{S_{G L}}{S} \times 100
$$

Where $S_{G L}$ is the surface of the glaze layer calculated through optical images of the wear tracks and $S$ is the surface of the wear track. From Figure 10a and b, it is observed that the formation of the glaze layer takes place at the beginning of the sliding process at $575^{\circ} \mathrm{C}\left(\mathrm{N}_{\mathrm{GL}}=20000\right.$ cycles [9]) and its destruction occurs when the temperature is decreased below $100^{\circ} \mathrm{C}$. However, by looking closer at the very beginning of the $100^{\circ} \mathrm{C}$ sequence, in Figure 10c it appears that the destruction of the glaze layer is not instantaneous. Indeed, there is an asymptotical decrease of the glaze layer coverage from $100 \%$ towards $0 \%$ in around 5000 fretting cycles which allows establishing a glaze layer "destruction" fretting cycles $N_{\text {dest }\left(100^{\circ}\right)} \approx 5000$ cycles. This transient evolution is also observed in the wear volume evolution $\mathrm{V}=\mathrm{f}(\mathrm{T})$ as detailed in Figure 10a underlining a change in the wear mechanisms. 


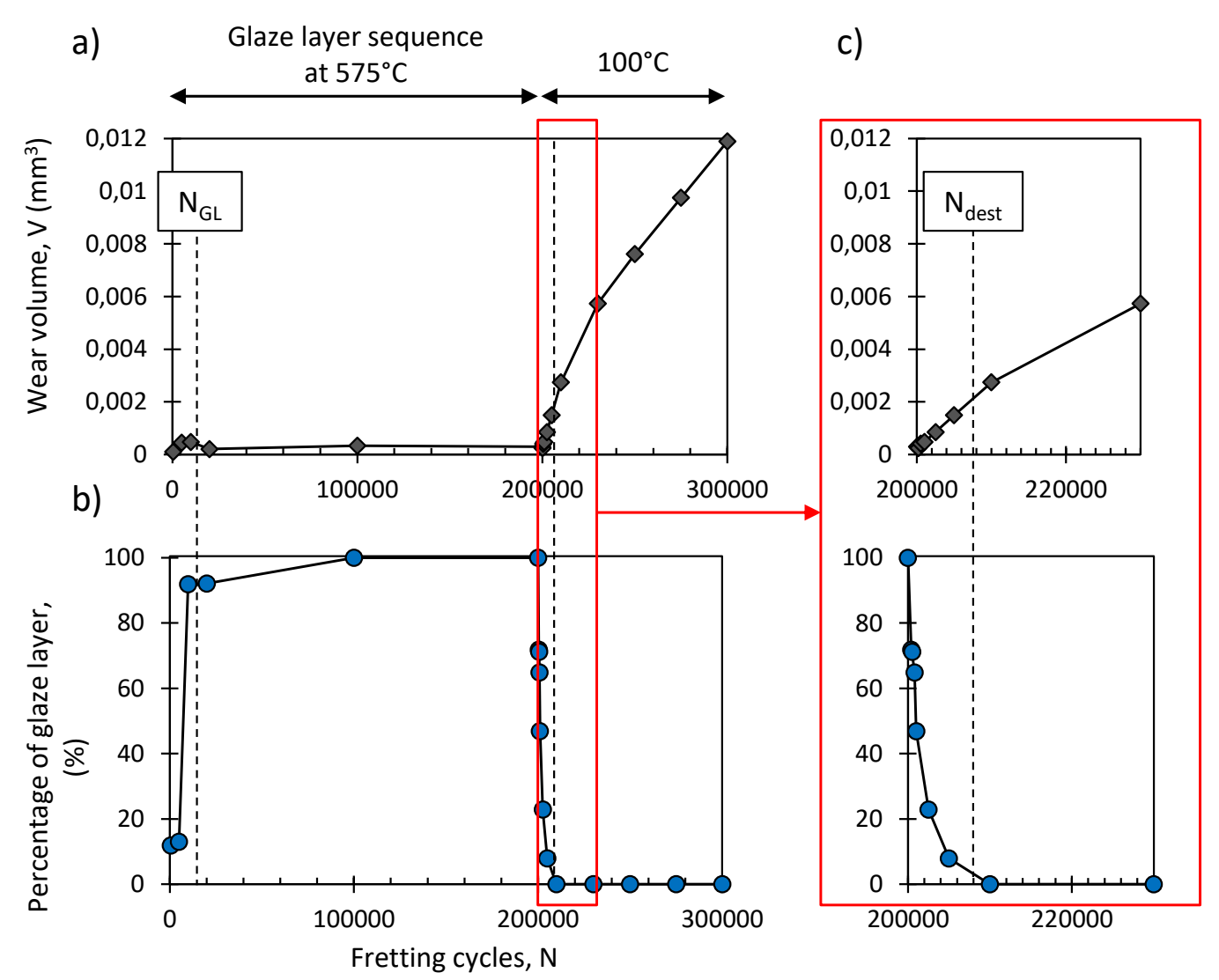

Figure 10: Evolution of a) the wear volume and b) the percentage of the glaze layer coverage as a function of the number of fretting cycles; $c$ ) zoom of the zone of interest $\left(f=50 \mathrm{~Hz}, \mathrm{P}=50 \mathrm{~N}, \delta_{0}= \pm 20 \mu \mathrm{m}\right)$.

\subsection{Morphological analysis}

Figure 11 shows the evolution of the wear scar morphology (optical images, 3D and 2D profilometry scans) over the fretting cycles of the low temperature bloc $\left(100^{\circ} \mathrm{C}\right)$ for VT and FT experiments. For a better readability of VT experiments (Figure $11 \mathrm{~b}$ ), the number of cycles starts at 0 but corresponds to $\mathrm{N}_{0}=200000$ cycles in Figure 9.

Figure 11a displays that the evolution of fretting scar morphology for FT experiments. It can be noticed that by increasing the fretting cycles, the contact area and wear depth increase and the fretting scar shifts from a W-shape to a U-shape scar after 10000 cycles. The presence of W-shape morphology reflects the presence of adhesive wear that is detected at the beginning of the experiment due to metal-metal interactions. These adhesive transfers will be progressively eliminated by wear extension shifting the interface to a purely $\mathrm{U}$-shaped abrasive wear scar.

In Figure 11b comparing wear scar morphology for VT experiments, it appears that the glaze layer created during the high temperature bloc does not disappear instantaneously when the temperature is reduced to $100^{\circ} \mathrm{C}$ (at $\mathrm{N}=0$ in Figure 11 ) but rather resists the low temperature fretting wear for around 5000 cycles (until $\mathrm{N}_{\text {dest }}$ cycles are achieved). The analysis of the profilometry scans, in 3D and $2 \mathrm{D}$, shows that there is no wear area extension for $\mathrm{N}_{0}<\mathrm{N}<\mathrm{N}_{\text {dest }}$. The wear seems to be very localized at some zones and not uniform over the surface, as it would be the case for pure abrasive wear. Hence, it appears here that the wear process is mainly driven by an adhesive mechanism [22,23]. After 5000 cycles, the glaze layer is totally destroyed from the interface and a pure abrasive 
wear process, characterized by a U-shape wear profile, takes place. Finally, the remaining glaze layer at the interface is directly related to the change of the slope of the wear kinetics in Figure 10.

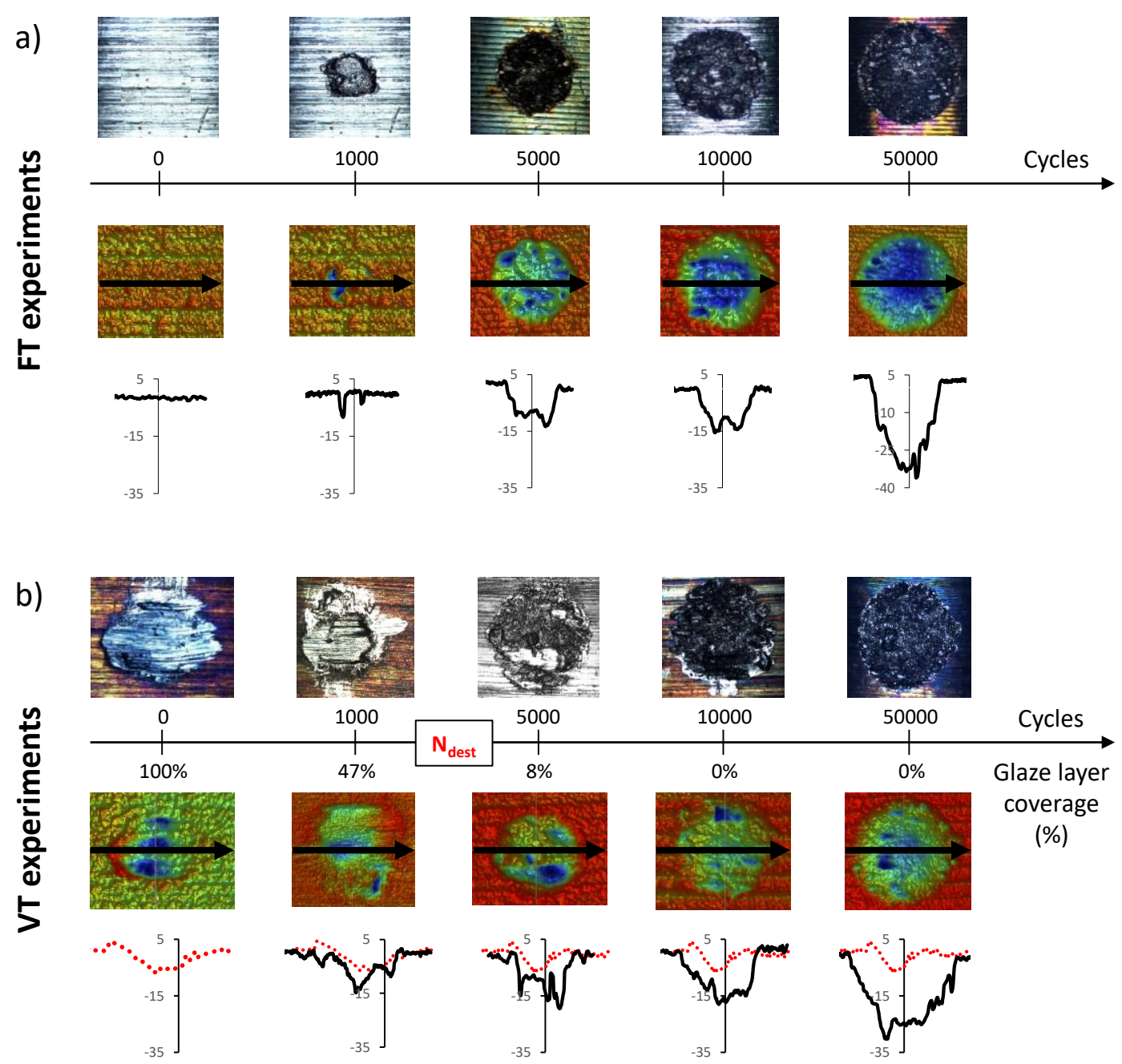

Figure 11: Evolution of the wear tracks over the fretting cycles: (a) Fixed Temperature experiment (FT experiment) and (b) Variable Temperature experiment (VT experiment) where the cycles are counted from 0 which corresponds to 200000 cycles in the Variable Temperature experiments $\left(f=50 \mathrm{~Hz}, P=50 \mathrm{~N}, \delta_{0}= \pm 20\right.$

$$
\mu \mathrm{m}, \mathrm{T}_{1}=100^{\circ} \mathrm{C} \text {. }
$$

\subsection{Analysis of the wear coefficients}

The analysis of the wear kinetics made at $100^{\circ} \mathrm{C}$ shows the necessity to study more carefully the Archard's wear coefficient evolution. Due to some wear mechanism changes during the wear process, the conventional linear Archard's wear description is no more reliable and a bi-linear wear description must be preferred (Figure 12). 

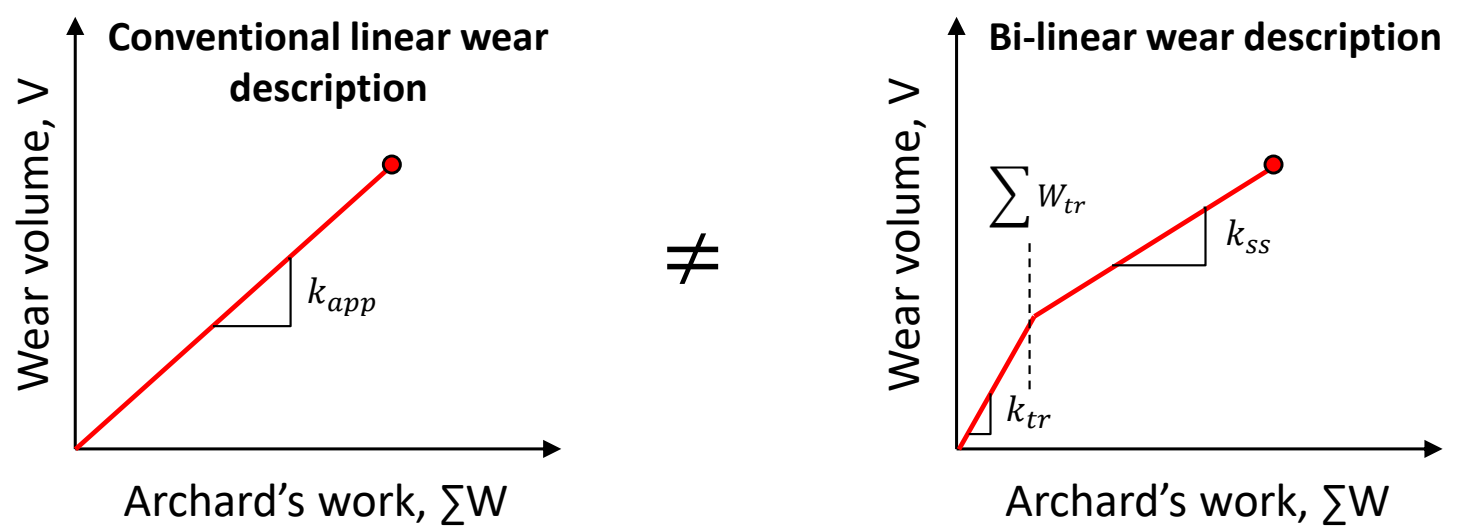

Figure 12: Illustration of the Archard's wear description (linear) and the bi-linear wear description.

Figure 13a presents the evolution of the wear volume as a function of the Archard's work for the FT and VT experiments. As expected, a significant fluctuation can be observed. Both FT and VT experiments display bilinear tendencies with a fast rising at the beginning characterized by a transient $\mathrm{k}_{\text {tr }}$ wear rate up to a threshold Archard work $\Sigma \mathrm{W}_{\mathrm{tr}}$ illustrating threshold wear damage (Figure $13 \mathrm{~b}$ and c). After this transient period, a steady state wear regime is observed characterized by a lower $k_{s s}$ steady wear rate. These various parameters are compiled in Table 3 and the corresponding wear rates are plotted in Figure 13d.

Table 3: Transient and steady-state Archard's wear coefficients.

\begin{tabular}{|c|c|c|}
\hline & $\begin{array}{c}\text { FT experiments at low } \\
\text { temperature }\left(100^{\circ} \mathrm{C}\right)\end{array}$ & $\begin{array}{c}\mathrm{VT} \text { experiments }\left(\mathrm{T}_{1}=\right. \\
\left.100^{\circ} \mathrm{C}\right)\end{array}$ \\
\hline$k_{t r}\left(\mathrm{~mm}^{3} / \mathrm{J}\right)$ & $1.0 \mathrm{E}-4$ & $6.3 \mathrm{E}-5$ \\
\hline$k_{s s}\left(\mathrm{~mm}^{3} / \mathrm{J}\right)$ & $5.3 \mathrm{E}-5$ & $3.5 \mathrm{E}-5$ \\
\hline$\sum W_{t r}(\mathrm{~J})$ & 71.8 & 25.6 \\
\hline
\end{tabular}

This analysis confirms that the Archard's coefficients $\left(k_{t r}\right.$ and $\left.k_{s s}\right)$ are lower for the VT experiments, underlining the beneficial effect of a pre-glaze layer on the wear process. During the transient regime, the lower Archard's coefficient for the VT experiments is explained by the presence of residual glaze layer at the interface which continues to act as a protective barrier against wear damage. However, the protective effect is not as efficient as it is at high temperature : $k_{s s}(G L)=$ $0 \mathrm{~mm}^{3} / J$ [9]. This beneficial effect could be explained by the protective effect of the initial glaze layer structure in addition to the reduction of the initial contact pressure. Indeed, for the FT interface, assuming an elastic hertzian contact, the initial contact radius was equal to $102 \mu \mathrm{m}$ and the mean contact pressure was equal to $2.3 \mathrm{GPa}$. For the VT experiments, the following low temperature sequence could lower the wear rate of the VT experiments so that $k_{t r}(F T)>k_{t r}(V T)$. The initial wear generated at high temperature inducing glaze layer formation extended the contact radius up to $370 \mu \mathrm{m}$. Hence, the absence of a high hertzian pressure at the beginning of the test also explains the fact that $k_{t r}(F T)>k_{t r}(V T)$. 


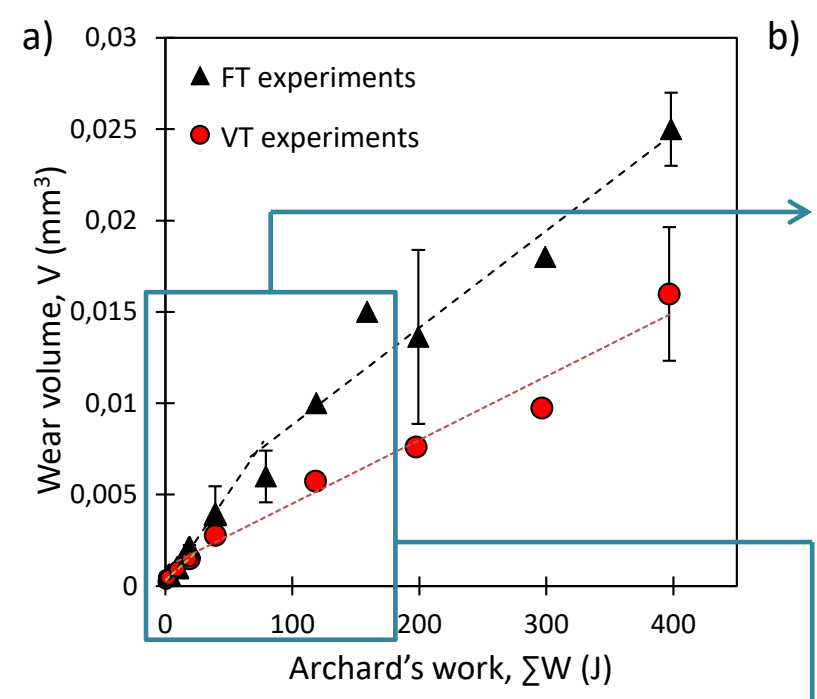

d)

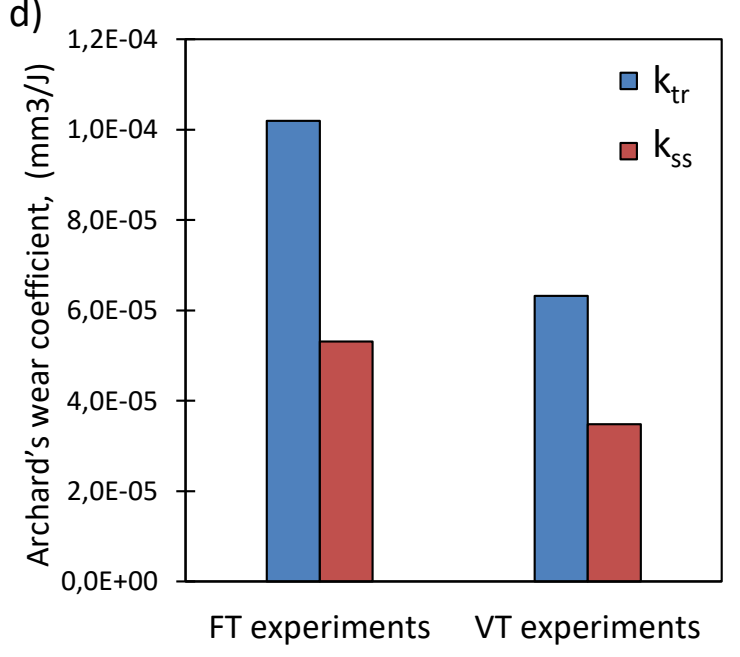

b)

c)
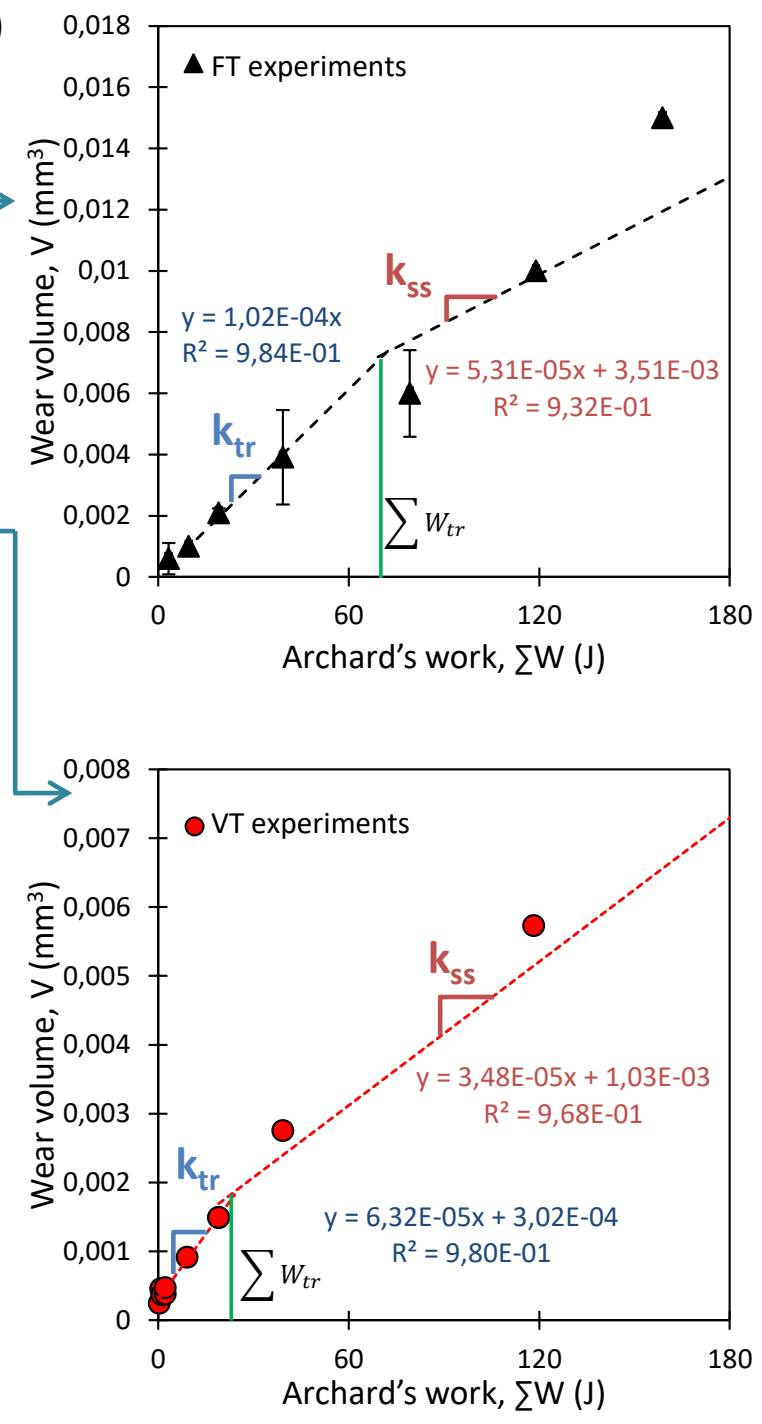

Figure 13: a) Evolution of the wear volume as a function of the Archard's work; b) zoom at the zone of interest for FT experiments; c) zoom at the zone of interest for VT experiments; d) comparison to the steady-state and transient Archard's wear coefficients for FT and VT experiments ( $f=50 \mathrm{~Hz}, \mathrm{P}=50 \mathrm{~N}, \delta_{0}= \pm 20 \mu \mathrm{m}, \mathrm{T}_{1}=100^{\circ} \mathrm{C}$ ).

It is interesting to note that $\Sigma \mathrm{W}_{\mathrm{tr}}$ is smaller for VT experiments which once again can be clarified assuming the third body theory. Indeed, it is classically admitted that the transient higher wear rate is mainly related to a direct severe metal-metal interactions [24]. When successive wear debris is generated in the fretted interface, an easier shear accommodation occurs favoring a lower steady wear regime. The faster is the debris generation, the faster the transition. Compared to FT experiments involving direct metal interactions (Figure 11), VT already displays a pre-glaze layer in the interface structure which, followed by the low temperature sliding, involves a fast activation of a complaint third body. Hence, this could illustrate the lower Archard's work observed for VT contacts compared to the usual FT situation (Table 3 \& Figure 13). The global wear extension can be described using the following formulation:

$$
\begin{gathered}
\text { If } \sum W<\sum W_{t r} \Rightarrow V=k_{t r} \times \sum W \\
\text { If } \sum W>\sum W_{t r} \Rightarrow V=k_{s s}\left(\sum W-\sum W_{t r}\right)+k_{t r} \sum W_{t r}
\end{gathered}
$$


If the low $k_{t r}$ and $\Sigma \mathrm{W}_{\mathrm{tr}}$ values of the VT can be easily interpreted, the lower steady state wear rates observed in the VT conditions are still questionable and will be discussed in the sections below. The steady-state wear volume $V_{S S}$ is extrapolated from the following equation.

$$
V_{s S}=V-V_{t r}=V-k_{t r} \sum W_{t r}
$$

A clear difference is observed between the FT and the VT experiments with a VT steady state wear rate about $30 \%$ lower than the one observed for the FT situation. To confirm that this difference is not only due to the difference in the surface area of the wear tracks, Figure $14 \mathrm{~b}$ plots the steadystate wear volume as a function of the surface area. Once again, VT experiments display a lower steady state wear volume compared to the FT experiments considering equal surface areas. It means that there is an additional effect related to the nature of the debris bed which needs to be considered to explain such difference.

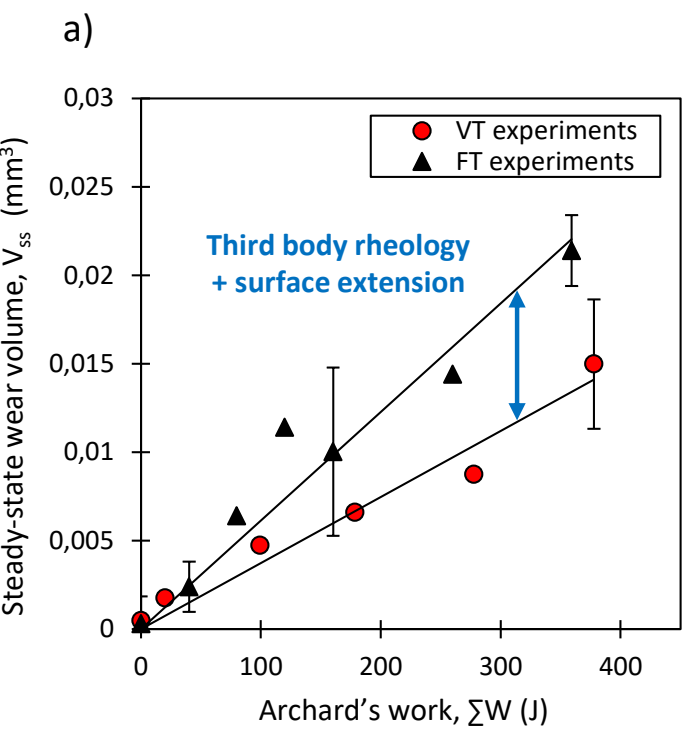

b)

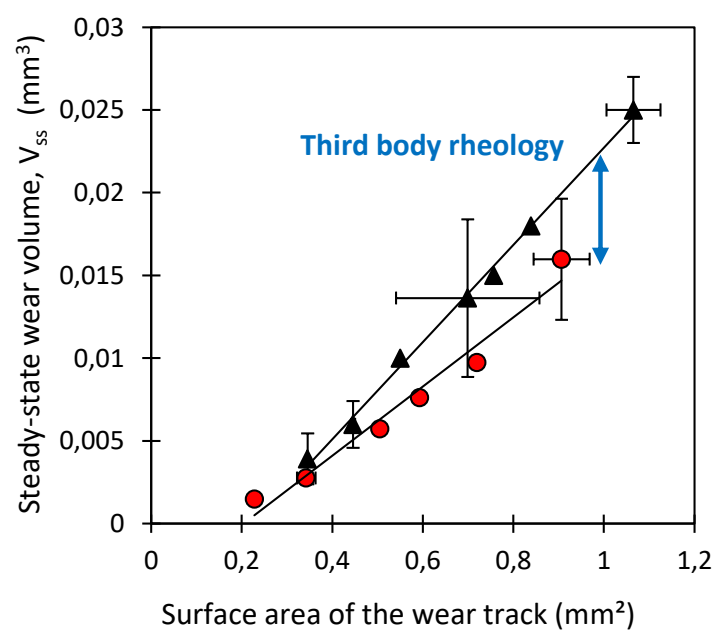

Figure 14: a) evolution of the steady-state wear volume as a function of the steady-state Archard's work ; b) evolution of the steady-state wear volume as a function of the surface area of the wear tracks $(f=50 \mathrm{~Hz}, P=50$ $\left.\mathrm{N}, \delta_{0}= \pm 20 \mu \mathrm{m}, \mathrm{T}_{1}=100^{\circ} \mathrm{C}\right)$. 


\subsection{Chemical analysis}

To strengthen these observations and to understand the way the intial glaze layer provides a memory effect, EDX analysis is performed. Figure 15 shows the evolution of the atomic $\mathrm{Co} / \mathrm{Cr}$ ratio over the fretting cycles for the FT and VT experiments. The initial ratio for the FT experiment is set to 2.1, which corresponds to the nominal ratio for HS25. For the VT experiments, the initial ratio is around 4 which also corresponds $\mathrm{Co} / \mathrm{Cr}$ ratio measured in the native glaze layer.

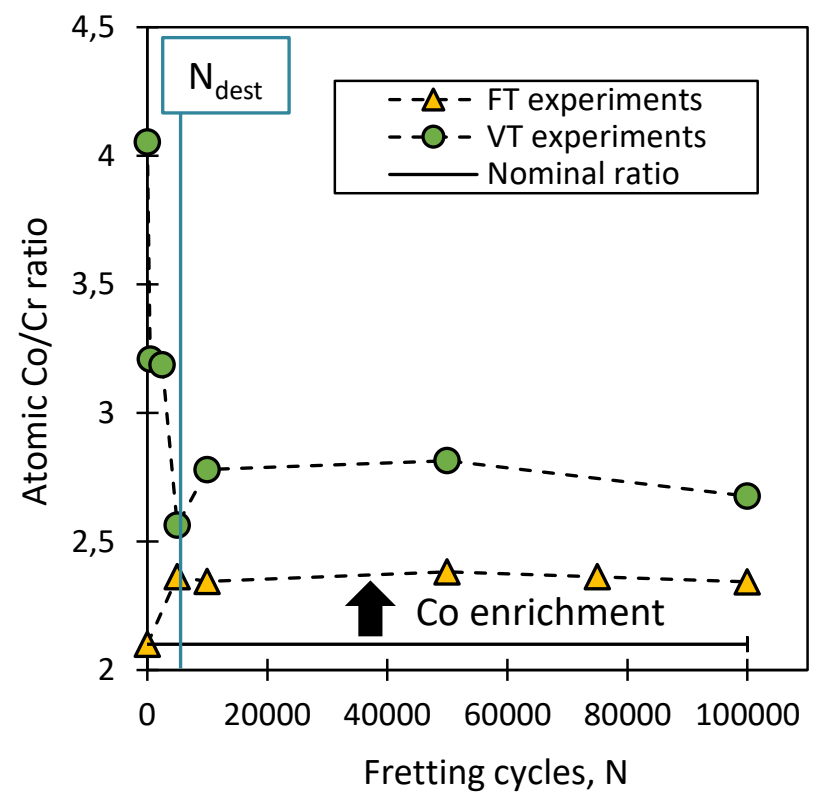

Figure 15: Evolution of the $\mathrm{Co} / \mathrm{Cr}$ atomic ratio over the fretting cycles. The cycles are counted from 0 which corresponds to 200000 cycles in the VT experiments.

For the FT experiments, the $\mathrm{Co} / \mathrm{Cr}$ ratio is constant over the fretting cycles (around 2.35) which is in accordance with the involved wear mechanism at such temperature, i.e. a continuous oxidation of the interface and its abrasion. For the VT experiments, $\mathrm{Co} / \mathrm{Cr}$ ratio decreases asymptotically when the initial glaze layer covers the entire wear tracks down to a steady state value around 2.7 after the entire destruction of the glaze layer ( $N>N_{\text {dest }}$ ). It is interesting to see that the $\mathrm{Co} / \mathrm{Cr}$ ratio of the VT experiments remains higher than that of the FT experiments (2.4 against 2.7) despite the fact that the glaze layer seems to be fully destroyed by low temperature fretting sliding. Hence, this analysis confirms that even if the glaze layer has been mechanically destroyed, the resulting debris bed remains enriched with cobalt long time after the glaze layer destruction.

This difference in the wear volume can be hence explained by the chemical nature of the debris bed as the formation of an initial glaze layer leads to a wear tracks richer in cobalt compared to the case without an initial glaze layer. It can be presumed that if the wear track is richer in cobalt, it means that the debris-bed layer embedded in the interface was also richer in cobalt. Then, the glaze layer, after being progressively destroyed, enriched the debris-bed layer in cobalt oxides. Cobalt oxides wear particles are known from previous study to be more cohesive due to their auto-diffusion properties [9] and may act as a more protective debris-bed layer (compared to the debris-bed without glaze layer debris) during the fretting wear process occurring at low temperature condition. 


\subsection{Discussion}

The analysis of the wear kinetics confirms a beneficial effect of the formation of an initial glaze layer when the interface is fretted at $100^{\circ} \mathrm{C}$. The wear kinetics displays a bi-linear evolution which is directly related to the progressive destruction of the glaze layer at the first phase and a linear abrasive wear process at the second phase (Figure 10 and Figure 13). In the transient regime, the glaze layer is able to resist the fretting wear at low temperature $\left(100^{\circ} \mathrm{C}\right)$ for a certain number of fretting cycles ( $\mathrm{N}_{\text {crit }}=5000$ cycles).

Optical and surface topography analysis (Figure 11) showed that there is no wear extension during the transient stage, and that the wear is highly localised at some zones of the wear tracks. Hence, the wear mechanism seems to be adhesive. This latency time before the complete destruction of the glaze layer at low temperature has, to our knowledge, never been reported in the literature. However, the mechanical properties of the glaze layer, which is nanocrystalline $[19,25,26]$, harder than the substrate $[9,13,14]$ and maybe more ductile $[9,13]$ explain this latency time. Nevertheless, it is believed that the main process delivering the exceptional tribological properties of the glaze layer is a continuous temperature-dependent sintering process of the oxidized particles embedded in the interface. If the temperature is too low, this continuous tribo-sintering process stops and the glaze layer ends up being destroyed.

Additionally, there is still a difference in terms of the wear volume and the friction coefficient depending if a glaze layer has been created or not at the interface before starting the fretting loadings at low temperature (Figure 14). This is attributed to the fact that the pre-existing glaze layer enriches the debris bed with cobalt oxides even after its destruction (Figure 15) which illustrates the memory effect as the latter plays a protective role against wear damage.

\section{Conclusion}

This paper focused on the effect of variable temperature on the glaze layer fretting wear HS25/alumina interface. The objective is to establish how the formation of a glaze layer affects the sliding process at lower temperature. The main points of the present paper are summarized as follows:

- The domain of the creation of the glaze layer $\left(T>300^{\circ} \mathrm{C}\right)$ is similar to the domain of the stability of the glaze layer. The introduction of an initial glaze layer structure is unable to prevent the fretting wear damage when the temperature is lowered below the threshold stability temperature $\mathrm{T}_{\mathrm{GL}}$.

- A small memory effect is observed at low temperature (i.e. low wear volume after introducing an initial pre-glaze layer) confirming that even if the glaze layer is destroyed and does not alter the wear mechanism involved at low temperature, it still has an influence on wear kinetics.

- Focusing on the sliding sequence $575^{\circ} \mathrm{C}-100^{\circ} \mathrm{C}$, it is observed that there is a latency time $\left(\mathrm{N}_{\text {dest }}\right)$ before the glaze layer is destroyed. This latency time has then an effect on the transient period of the sliding process.

- The "memory" effect of the glaze layer, leading to a reduction of the wear volume compared to a simple fretting-wear test at low temperature, is attributed to the chemical nature of the debris bed which is enriched in cobalt by the former glaze layer increasing in turn the cohesive properties of the third body and consequently reducing wear. 


\section{Acknowledgements}

This research did not receive any specific grant from funding agencies in the public, commercial, or not-for-profit sectors.

\section{References}

[1] F.H. Stott, J. Glascott, G.C. Wood, The sliding wear of commercial Fe- $12 \% \mathrm{Cr}$ alloys at high temperature, Wear. 101 (1985) 311-324.

[2] R. Rybiak, S. Fouvry, B. Bonnet, Fretting wear of stainless steels under variable temperature conditions: Introduction of a "composite" wear law, Wear. 268 (2010) 413-423. https://doi.org/10.1016/j.wear.2009.08.029.

[3] I.A. Inman, P.S. Datta, Studies of high temperature sliding wear of metallic dissimilar interfaces IV: Nimonic 80A versus Incoloy 800HT, Tribol. Int. 44 (2011) 1902-1919. https://doi.org/10.1016/j.triboint.2011.08.004.

[4] F.H. Stott, D.S. Lin, G.C. Wood, The structure and mechanism of formation of the 'glaze' oxide layers produced on nickel-based alloys during wear at high temperatures, Corros. Sci. 13 (1973) 449-469. https://doi.org/10.1016/0010-938X(73)90030-9.

[5] A. Viat, A. Dreano, S. Fouvry, M.-I. De Barros Bouchet, J.-F. Henne, Fretting wear of pure cobalt chromium and nickel to identify the distinct roles of HS25 alloying elements in high temperature glaze layer formation, Wear. 376-377 (2017) 1043-1054. https://doi.org/10.1016/j.wear.2017.01.049.

[6] A. Korashy, H. Attia, V. Thomson, S. Oskooei, Fretting wear behavior of cobalt - Based superalloys at high temperature - A comparative study, Tribol. Int. 145 (2020) 106155. https://doi.org/10.1016/j.triboint.2019.106155.

[7] A. Korashy, H. Attia, V. Thomson, S. Oskooei, Characterization of fretting wear of cobalt-based superalloys at high temperature for aero-engine combustor components, Wear. 330 (2015) 327-337. https://doi.org/10.1016/j.wear.2014.11.027.

[8] H. Kato, K. Komai, Tribofilm formation and mild wear by tribo-sintering of nanometer-sized oxide particles on rubbing steel surfaces, Wear. 262 (2007) 36-41. https://doi.org/10.1016/j.wear.2006.03.046.

[9] A. Dreano, S. Fouvry, G. Guillonneau, Understanding and formalization of the fretting-wear behavior of a cobalt-based alloy at high temperature, Wear. 452-453 (2020). https://doi.org/10.1016/j.wear.2020.203297.

[10] H. Kato, Severe-mild wear transition by supply of oxide particles on sliding surface, Wear. 255 (2003) 426-429. https://doi.org/10.1016/S0043-1648(03)00077-2.

[11] J. Jiang, F.H. Stott, M.M. Stack, The role of triboparticulates in dry sliding wear, Tribol. Int. 31 (1998) 245-256. https://doi.org/10.1016/S0301-679X(98)00027-9.

[12] F.H. Stott, G.C. Wood, The influence of oxides on the friction and wear of alloys, Tribol. Int. 11 (1978) 211-218. https://doi.org/10.1016/0301-679X(78)90178-0.

[13] A. Viat, G. Guillonneau, S. Fouvry, G. Kermouche, S. Sao Joao, J. Wehrs, J. Michler, J.-F. Henne, 
Brittle to ductile transition of tribomaterial in relation to wear response at high temperatures, Wear. 392-393 (2017) 60-68. https://doi.org/10.1016/j.wear.2017.09.015.

[14] C. Rynio, H. Hattendorf, J. Klöwer, G. Eggeler, The evolution of tribolayers during high temperature sliding wear, Wear. 315 (2014) 1-10. https://doi.org/10.1016/j.wear.2014.03.007.

[15] A. Viat, S. Fouvry, M.-I. De Barros Bouchet, L. Pin, Influence of carbon-based solid lubricant on fretting wear response for alumina-based ceramics versus cobalt superalloy contact, Surf. Coatings Technol. 284 (2015) 327-333. https://doi.org/10.1016/j.surfcoat.2015.07.043.

[16] C. Mary, S. Fouvry, J.M. Martin, B. Bonnet, Pressure and temperature effects on Fretting Wear damage of a Cu-Ni-In plasma coating versus Ti17 titanium alloy contact, Wear. 272 (2011) 1837. https://doi.org/10.1016/j.wear.2011.06.008.

[17] C. Mary, Simulation expérimentale de l'usure du contact aube/disque de compresseur sous sollicitations de fretting, Ecole Centrale de Lyon, 2009.

[18] J. Glascott, G.C. Wood, F.H. Stott, The Influence of Experimental Variables on the Development and Maintenance of Wear-Protective Oxides during Sliding of High-Temperature Iron-Base Alloys, Proc. Inst. Mech. Eng. Part C J. Mech. Eng. Sci. 199 (1985) 35-41. https://doi.org/10.1243/PIME_PROC_1985_199_088_02.

[19] A. Dreano, S. Fouvry, S. Sao Joao, J. Galipaud, G. Guillonneau, The formation of a cobalt-based glaze layer at high temperature: a layered structure, Wear. 440-441 (2019). https://doi.org/https://doi.org/10.1016/j.wear.2019.203101.

[20] A. Dreano, S. Fouvry, G. Guillonneau, A combined friction energy and tribo-oxidation formulation to describe the high temperature fretting wear response of a cobalt-based alloy, Wear. 426-427 (2019) 712-724. https://doi.org/10.1016/j.wear.2019.01.023.

[21] A. Dreano, S. Fouvry, G. Guillonneau, A tribo-oxidation abrasive wear model to quantify the wear rate of a cobalt-based alloy subjecting to fretting in low to medium temperature conditions, Tribol. Int. 125 (2018) 128-140. https://doi.org/10.1016/j.triboint.2018.04.032.

[22] S. Baydoun, S. Fouvry, S. Descartes, P. Arnaud, Fretting wear rate evolution of a flat-on-flat low alloyed steel contact: A weighted friction energy formulation, Wear. 426-427 (2019) 676693. https://doi.org/https://doi.org/10.1016/j.wear.2018.12.022.

[23] S. Baydoun, S. Fouvry, An experimental investigation of adhesive wear extension in fretting interface: Application of the contact oxygenation concept, Tribol. Int. 147 (2020) 106266. https://doi.org/10.1016/j.triboint.2020.106266.

[24] S. Baydoun, P. Arnaud, S. Fouvry, Modelling adhesive wear extension in fretting interfaces: An advection-dispersion-reaction contact oxygenation approach, Tribol. Int. 151 (2020) 106490. https://doi.org/10.1016/j.triboint.2020.106490.

[25] A. Viat, M.-I. De Barros Bouchet, B. Vacher, T. Le Mogne, S. Fouvry, J.-F. Henne, Nanocrystalline glaze layer in ceramic-metallic interface under fretting wear, Surf. Coatings Technol. 308 (2016) 307-315. https://doi.org/10.1016/j.surfcoat.2016.07.100.

[26] C. Rynio, H. Hattendorf, J. Klöwer, G. Eggeler, On the physical nature of tribolayers and wear debris after sliding wear in a superalloy/steel tribosystem at 25 and $300^{\circ} \mathrm{C}$, Wear. 317 (2014) 26-38. https://doi.org/10.1016/j.wear.2014.04.022. 